\title{
Merkel Cell Carcinoma Concomitant with Invasive Bowen's Disease: Immunohistochemical Investigation of Tumor-Infiltrating Leukocytes
}

\author{
Hisayuki Tono Taku Fujimura Eimei Iwama Yoshiyuki Kusakari \\ Sadanori Furudate Yumi Kambayashi Takahiro Haga Akira Hashimoto \\ Setsuya Aiba \\ Department of Dermatology, Tohoku University Graduate School of Medicine, Sendai, \\ Japan
}

\section{Key Words}

Invasive Bowen's disease · Merkel cell carcinoma · Tumor-infiltrating leukocytes · CD8 ·

Caspase 3

\begin{abstract}
Merkel cell carcinoma (MCC) is an aggressive, cutaneous, neuroendocrine carcinoma and, in rare cases, occurs with Bowen's disease (BD). In this report, we describe a case of MCC concurrent with invasive BD and compare the profiles of tumor-infiltrating leukocytes in the lesional skin of MCC and invasive BD. Interestingly, immunohistochemical study revealed significant numbers of $C D 8+$ cells and caspase 3-expressing cells in the same areas of invasive $\mathrm{BD}$ and MCC. Our present case suggests that MCC concurrent with invasive BD might have a good prognosis because of the substantial number of $C D 8+$ cells in the tumor.
\end{abstract}

(C) 2015 S. Karger AG, Basel

\section{Introduction}

Merkel cell carcinoma (MCC) is an aggressive, cutaneous, neuroendocrine carcinoma that originates from either Merkel cells or from pluripotent stem cells in the basal layer of the epidermis $[1,2]$. Recent reports suggested that the type of tumor-infiltrating leukocytes (TILs) could determine the prognosis and tumor-specific survival of MCC [3-5]. Bowen's disease (BD) is defined as carcinoma in situ; the tumor shows atypical pleomorphism, cell

KARGER 125/s $\quad \begin{aligned} & \text { Taku Fujimura } \\ & \text { Department of Dermatology } \\ & \text { Tohoku University Graduate School of Medicine } \\ & \text { Seiryo-machi 1-1, Aoba-ku, Sendai 980-8574 (Japan) } \\ & \text { E-Mail tfujimura1@mac.com }\end{aligned}$


Tono et al.: Merkel Cell Carcinoma Concomitant with Invasive Bowen's Disease: Immunohistochemical Investigation of Tumor-Infiltrating Leukocytes

clumping, irregular mitosis and individual cell keratinization. BD progresses to invasive BD, with the cytological characteristics of BD [6]. In addition, as we previously reported, both invasive and non-invasive BD contain substantial numbers of TILs, including CD8+ cells, Foxp3+ regulatory T cells (Tregs) and CD163+ macrophages [7]. Although several cases of MCC concurrent with BD have already been reported $[8,9]$, there has been no English language report investigating TILs in MCC with BD. In this report, we describe a case of MCC concurrent with invasive BD and compare the profiles of TILs in the lesional skin of MCC and invasive BD.

\section{Case Report}

A 71-year-old Japanese male visited our outpatient clinic with a 6-month history of a rapidly growing red plaque on his back. On his initial visit, physical examination revealed a red, pigmented plaque, $90 \times 80 \mathrm{~mm}$, with a dome-shaped elastic-soft nodule (fig. 1a). The diameter of the nodule was approximately $20 \mathrm{~mm}$. A skin biopsy from the edge of the plaque revealed atypical squamous cells containing large oval nuclei with occasional conspicuous nucleoli, with individual keratinization, mitotic figures and clumping cells. In addition, the biopsy specimen from the center of the nodule revealed dense infiltrating atypical squamous cells throughout the dermis (fig. 1c). We first diagnosed this patient as invasive BD and excised the tumor with a 5-mm margin. Unexpectedly the histological finding of the whole tumor revealed that the squamous cell-composed tumor was surrounded by another type of tumor composed of small round cells with scant cytoplasm and oval nuclei (fig. 1b, d). These small round cells were positive for AE1/AE3, cytokeratin 20, synaptophysin and CD56, and negative for $34 \beta \mathrm{E} 12$, cytokeratin 7 , chromogranin A and TTF1. From the above findings, we diagnosed this tumor as MCC concomitant with invasive BD. We screened for a possible internal malignancy with positron emission tomography computed tomography and found no evidence of metastasis.

As we and other reports suggested $[3,4,7]$, both invasive BD and MCC contain substantial numbers of immunoreactive and immunosuppressive cells. Notably, a previous report even suggested that the number of tumor-infiltrating CD8+ cells determines the prognosis of MCC [3]. Therefore, we further employed immunohistochemical staining for CD8 (fig. 2a, b), caspase 3 (fig. 2c, d), Foxp3 (fig. 3a, b), CD163 (fig. 3c, d) and CD206 (fig. 3e, f) in the lesional areas of invasive BD and MCC. Substantial numbers of immunoreactive and immunosuppressive cells were detected at the edge of the tumor in invasive BD, whereas TILs were scattered at the center of the tumor in MCC. Both invasive BD and MCC contained caspase 3expressing cells in the CD8-infiltrated areas, which suggested induction of an anti-tumor immune response in the tumor microenvironment by CD8+ cytotoxic T cells.

\section{Discussion}

Previous reports suggested the importance of evaluating the tumor microenvironment in the lesional skin of MCC. Indeed, Paulson et al. [3] reported an association between the infiltration of intratumoral CD8+ lymphocytes and improved MCC-specific survival. More recently, Dowlatshahi et al. [4] reported that a subset of tumor-associated macrophages (TAMs) in MCC expressed PD-L1, which contributes to the exhaustion of CD8+ effector $\mathrm{T}$ cells in the tumor microenvironment. Indeed, Afanasiev et al. [10] reported that Merkel cell polyomavirus (MCPyV)-specific CD8 T cells were detected directly ex vivo from the 
Tono et al.: Merkel Cell Carcinoma Concomitant with Invasive Bowen's Disease: Immunohistochemical Investigation of Tumor-Infiltrating Leukocytes

blood samples of patients with MCPyV-positive MCC. Interestingly, MCPyV-specific CD8 $\mathrm{T}$ cells and MCC-infiltrating lymphocytes expressed higher levels of therapeutically targetable PD-1 [10]. Notably, MCPyV contributes to the carcinogenesis of MCC [11]. From an immunological point of view, recent reports also suggested that the expression of B7-H molecules, including PD-L1, on TAMs and tolerogenic dendritic cells is regulated by Tregs, and that the induction of Tregs is mediated by TAMs by B7-H-related signaling [12]. In aggregate, these reports suggested the significance of crosstalk between Tregs and TAMs in the lesional skin of MCC, and these immunosuppressive cells might contribute to the exhaustion of MCCspecific CD8+ T cells to maintain an immunosuppressive tumor microenvironment.

Concerning BD, we previously reported that substantial numbers of CD8+ cells were detected adjacent to tumor cells, and that the expression of PD-L1 on tumor cells diminished in parallel with the progression of $\mathrm{BD}$, which might recover the exhausted CD8+ effector T cells in the tumor microenvironment of invasive BD, like MCC $[4,7]$. Notably, although several cases of MCC concurrent with BD have already been reported [8,9], to our knowledge, there is no English language report suggesting a prognostic factor for this type of tumor. In this report, we describe a case of MCC concurrent with invasive BD and compare the profiles of TILs in the lesional skin of MCC and invasive BD. Interestingly, immunohistochemical study revealed that both invasive BD and MCC contained significant numbers of CD8+ cells in the tumor lesion. Although this area contained substantial number of Foxp3+ Tregs and CD163+ TAMs, caspase 3-expressing cells were scattered in the lesional skin of BD and MCC, which might suggest induction of an anti-tumor immune response in the tumor microenvironment of MCC and BD. Our present case suggests that MCC concurrent with invasive BD might have a good prognosis because of the substantial number of CD8+ cells in the tumor. Since we did not directly assess the suppressive functions of these infiltrating cells, further analysis of the mechanisms underlying this phenomenon could offer fundamental insights into the mechanisms of our case. To confirm this hypothesis, further studies will be necessary in the future.

\section{References}

1 Ferringer T, Rogers HC, Metcalf JS: Merkel cell carcinoma in situ. J Cutan Pathol 2005;32:162-165.

2 Van Keymeulen A, Mascre G, Youseff KK, Harel I, Michaux C, De Geest N, Szpalski C, Achouri Y, Bloch W, Hassan BA, Blanpain C: Epidermal progenitors give rise to Merkel cells during embryonic development and adult homeostasis. J Cell Biol 2009;187:91-100.

-3 Paulson KG, Iyer JG, Tegeder AR, Thibodeau R, Schelter J, Koba S, Schrama D, Simonson WT, Lemos BD, Byrd DR, Koelle DM, Galloway DA, Leonard JH, Madeleine MM, Argenyi ZB, Disis ML, Becker JC, Cleary MA, Nghiem P: Transcriptome-wide studies of Merkel cell carcinoma and validation of intratumoral CD8+ lymphocyte invasion as an independent predictor of survival. J Clin Oncol 2011;29:1539-1546.

-4 Dowlatshahi M, Huang V, Gehad AE, Jiang Y, Calarese A, Teague JE, Dorosario AA, Cheng J, Nghiem P, Schanbacher CF, Thakuria M, Schmults CD, Wang LC, Clark RA: Tumor-specific T cells in human Merkel cell carcinomas: a possible role for Tregs and T-cell exhaustion in reducing T-cell responses. J Invest Dermatol 2013;133:1879-1889.

5 Asgari MM, Sokil MM, Warton EM, Iyer J, Paulson KG, Nghiem P: Effect of host, tumor, diagnostic, and treatment variables on outcomes in a large cohort with Merkel cell carcinoma. JAMA Dermatol 2014;150: 716-723.

6 Mii S, Amoh Y, Tanabe K, Kitasato H, Sato Y, Katsuoka K: Nestin expression in Bowen's disease and Bowen's carcinoma associated with human papillomavirus. Eur J Dermatol 2011;21:515-519.

7 Furudate S, Fujimura T, Kambayashi Y, Aiba S: Comparison of immunosuppressive cells and cytotoxic cells in invasive and non-invasive Bowen's disease. Acta Derm Venereol 2014;94:337-339.

8 Ishida M, Okabe H: Merkel cell carcinoma concurrent with Bowen's disease: two cases, one with an unusual immunophenotype. J Cutan Pathol 2013;40:839-843.

-9 Sirikanjanapong S, Melamed J, Patel RR: Intraepidermal and dermal Merkel cell carcinoma with squamous cell carcinoma in situ: a case report with review of literature. J Cutan Pathol 2010;37:881-885. 


\section{Case Reports in Dermatology}

\begin{tabular}{l|l}
\hline \multicolumn{2}{l}{ Case Rep Dermatol 2015;7:1-6 } \\
\hline DOI: 10.1159/000371732 & $\begin{array}{l}\text { (c) 2015 S. Karger AG, Basel } \\
\text { www.karger.com/cde }\end{array}$ \\
\hline
\end{tabular}

Tono et al.: Merkel Cell Carcinoma Concomitant with Invasive Bowen's Disease: Immunohistochemical Investigation of Tumor-Infiltrating Leukocytes

10 Afanasiev OK, Yelistratova L, Miller N, Nagase K, Paulson K, Iyer JG, Ibrani D, Koelle DM, Nghiem P: Merkel polyomavirus-specific T cells fluctuate with Merkel cell carcinoma burden and express therapeutically targetable PD-1 and Tim-3 exhaustion markers. Clin Cancer Res 2013;19:5351-5360.

11 Feng H, Shuda M, Chang Y, Moore PS: Clonal integration of a polyomavirus in human Merkel cell carcinoma. Science 2008;319:1096-1100.

-12 Fujimura T, Ring S, Umansky V, Mahnke K, Enk AH: Regulatory T cells stimulate B7-H1 expression in myeloid-derived suppressor cells in ret melanomas. J Invest Dermatol 2012;132:1239-1246.
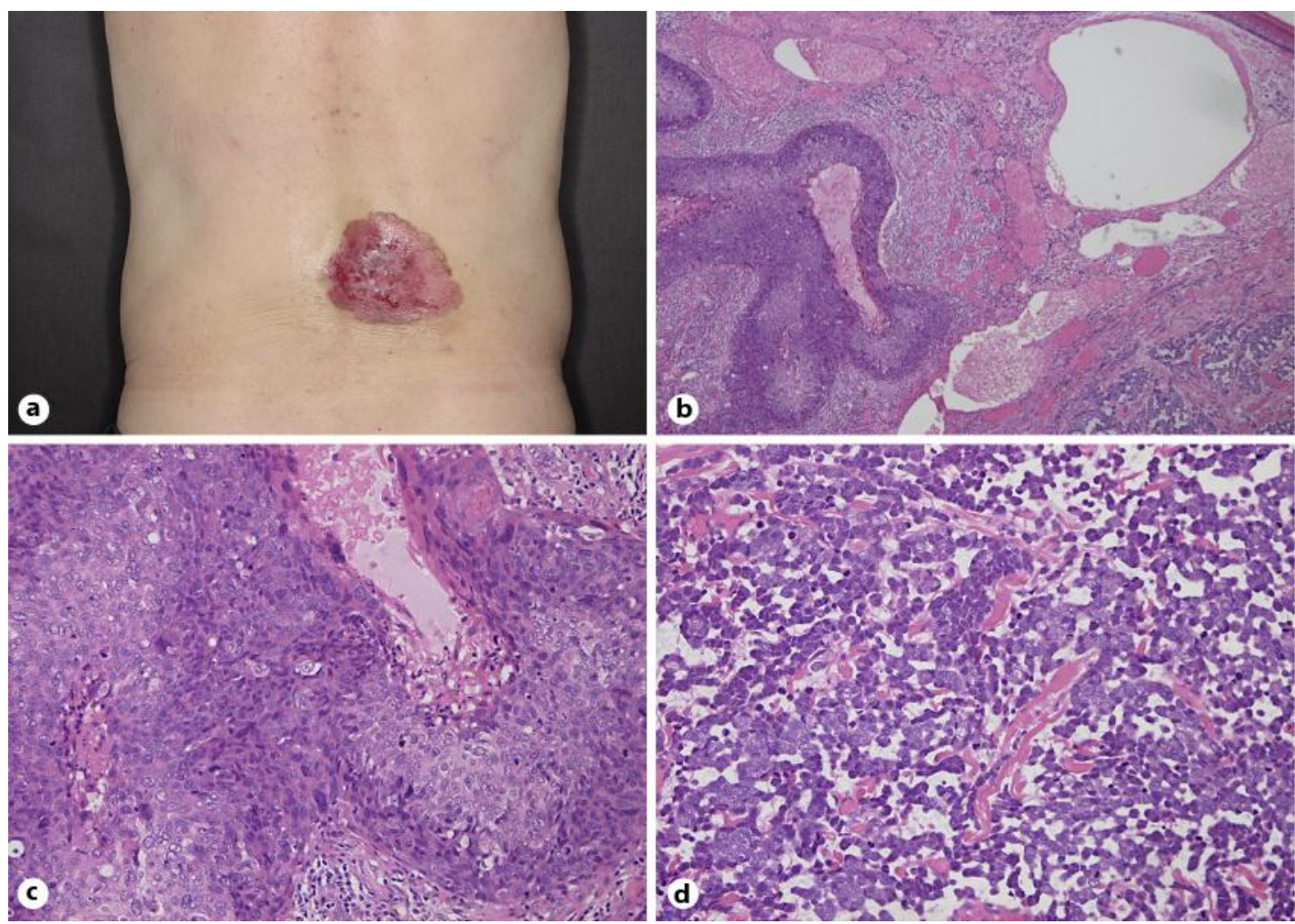

Fig. 1. a Red, pigmented plaque on the back, $90 \times 80 \mathrm{~mm}$, with a dome-shaped elastic-soft nodule. $\mathbf{b}$ The squamous cell-composed tumor was surrounded by another type of tumor. c Center of the tumor (squamous cell-composing tumor area): the atypical squamous cells contained large oval nuclei and occasionally conspicuous nucleoli, with individual keratinization, mitotic figures and clumping cells. $\mathbf{d}$ Peripheral areas of the tumor: small round cells with scant cytoplasm and oval nuclei. Original magnification: $\mathbf{b} \times 50$; c, $\mathbf{d} \times 200$. 


\section{Case Reports in Dermatology}

\begin{tabular}{l|l}
\hline \multicolumn{2}{l}{ Case Rep Dermatol 2015;7:1-6 } \\
\hline DOI: 10.1159/000371732 & $\begin{array}{l}\text { (c) 2015 S. Karger AG, Basel } \\
\text { www.karger.com/cde }\end{array}$ \\
\hline
\end{tabular}

Tono et al.: Merkel Cell Carcinoma Concomitant with Invasive Bowen's Disease: Immunohistochemical Investigation of Tumor-Infiltrating Leukocytes
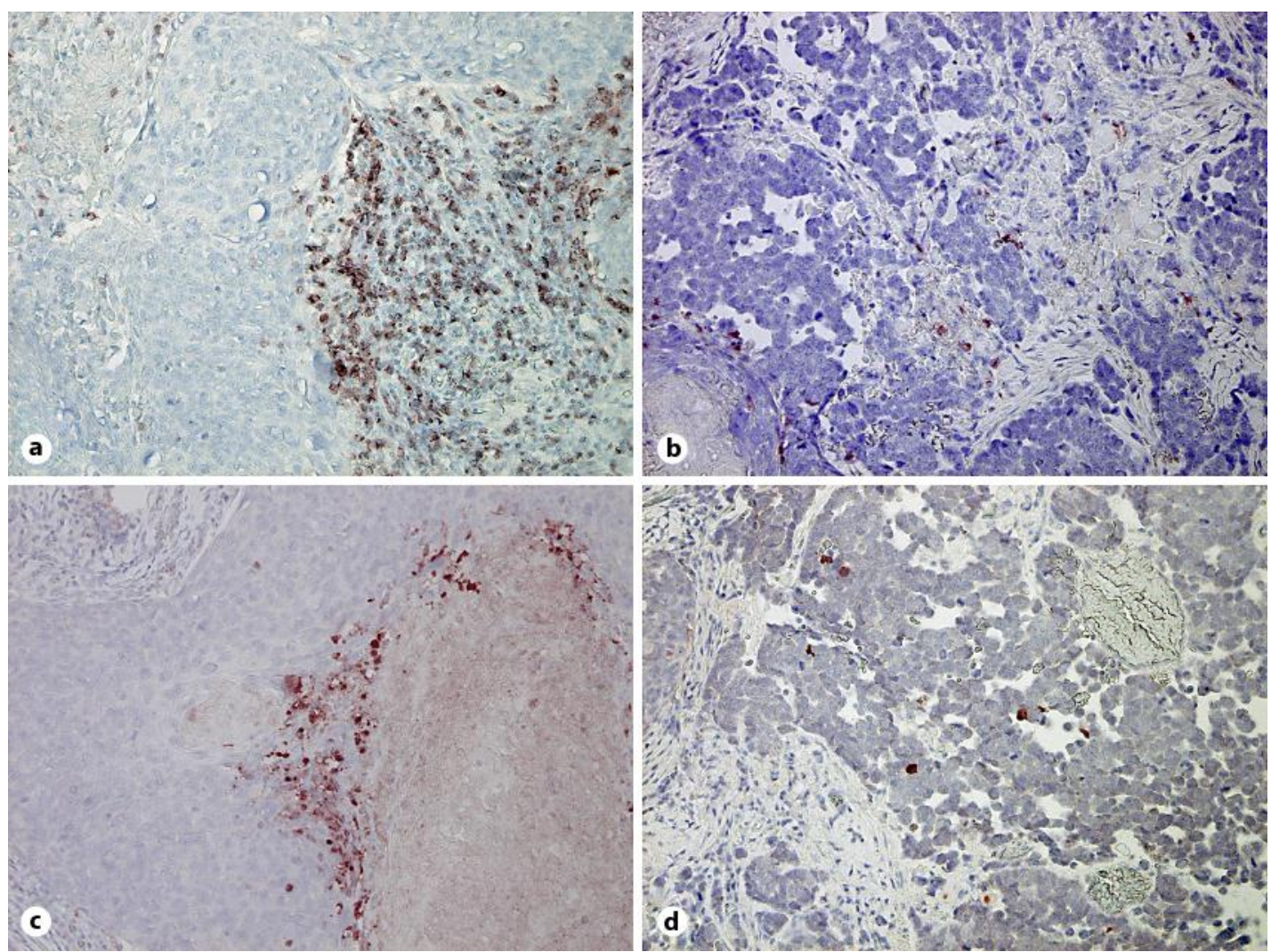

Fig. 2. CD8+ cells and caspase 3+ cells in the areas of invasive BD and MCC. Paraffin-embedded tissue samples were deparaffinized and stained with anti-CD8 antibody (a, b) and anti-caspase 3 antibody (c, d) for the areas of invasive BD $(\mathbf{a}, \mathbf{c})$ and MCC $(\mathbf{b}, \mathbf{d})$. The sections were developed with liquid permanent red. Original magnification: $\times 200$. 


\section{Case Reports in Dermatology}

\begin{tabular}{l|l}
\hline Case Rep Dermatol 2015;7:1-6 \\
\hline DOI: $10.1159 / 000371732$ & $\begin{array}{l}\text { C 2015 S. Karger AG, Basel } \\
\text { www.karger.com/cde }\end{array}$ \\
\hline
\end{tabular}

Tono et al.: Merkel Cell Carcinoma Concomitant with Invasive Bowen's Disease: Immunohistochemical Investigation of Tumor-Infiltrating Leukocytes
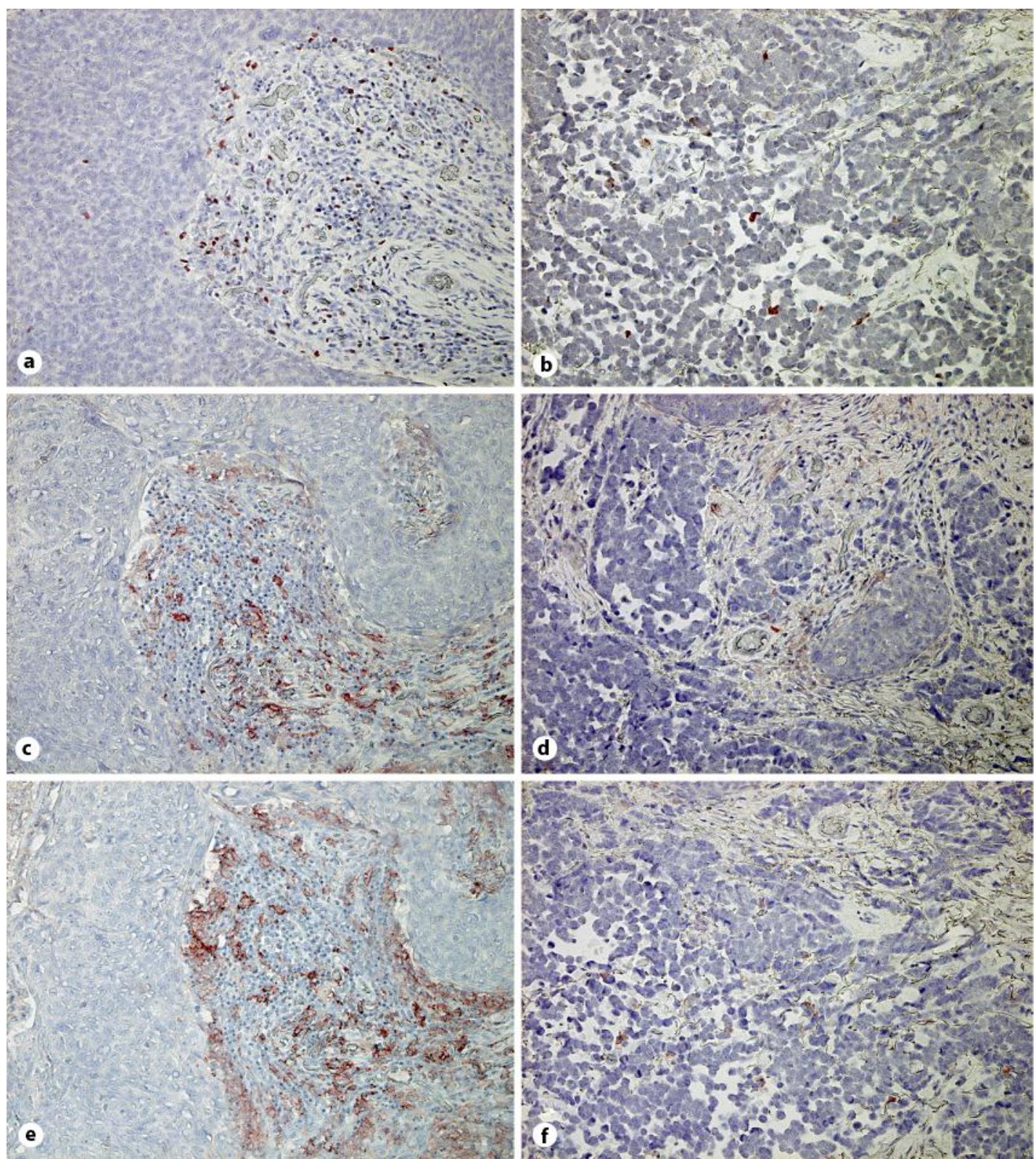

Fig. 3. Foxp3+ Tregs, CD163+ macrophages and CD206+ cells in the areas of invasive BD and MCC. Paraffin-embedded tissue samples were deparaffinized and stained with anti-Foxp3 antibody (a, b), anti-CD163 antibody (c, d) and anti-CD206 antibody (e, f) for the areas of invasive BD (a, c, e) and MCC (b, d, f). The sections were developed with liquid permanent red. Original magnification: $\times 200$. 